\title{
Laboreal
}

Volume $14 \mathrm{~N}^{\circ} 1$ | 2018

O regresso ao emprego após um acidente de trabalho

\section{Os sinistrados no trabalho e o direito à reparação: percursos pós-sinistro de contacto com as instituições}

Los siniestrados en el trabajo y el derecho a la reparación: trayectos postaccidente al contacto con las instituciones

Les victimes d'accidents de travail et le droit à la réparation: parcours postsinistre au contact des institutions

The injured at work and the right to reparation: the institutional contacts after the accident

\section{Vanessa Rodrigues}

\section{(2) OpenEdition}

\section{Journals}

\section{Edição electrónica}

URL: http://journals.openedition.org/laboreal/552

DOI: $10.4000 /$ laboreal.552

ISSN: 1646-5237

\section{Editora}

Universidade do Porto

\section{Refêrencia eletrónica}

Vanessa Rodrigues, « Os sinistrados no trabalho e o direito à reparação: percursos pós-sinistro de contacto com as instituições », Laboreal [Online], Volume 14 N$^{0} 1$ | 2018, posto online no dia 01 julho 2018, consultado o 07 outubro 2019. URL : http://journals.openedition.org/laboreal/552 ; DOI : 10.4000/laboreal.552

Este documento foi criado de forma automática no dia 7 outubro 2019

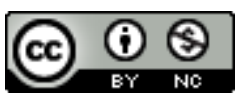

Laboreal está licenciado com uma Licença Creative Commons - Atribuição-NãoComercial 4.0 Internacional. 


\section{Os sinistrados no trabalho e o} direito à reparação: percursos póssinistro de contacto com as instituições

Los siniestrados en el trabajo y el derecho a la reparación: trayectos postaccidente al contacto con las instituciones

Les victimes d'accidents de travail et le droit à la réparation: parcours postsinistre au contact des institutions

The injured at work and the right to reparation: the institutional contacts after the accident

\section{Vanessa Rodrigues}

\section{NOTA DO EDITOR}

http://dx.doi.org/10.15667/laborealxiv0118vr

Manuscrito recebido em:janeiro/2018

Aceite após peritagem: março/2018

\section{Introdução}

1 O projeto 'Regresso ao trabalho após acidente: superar obstáculos' ${ }^{[1]}$, que decorreu entre 2016 e 2017, teve como principal objetivo o aprofundamento do conhecimento existente sobre as etapas biográficas subsequentes à ocorrência de um acidente de trabalho. A face mais visível deste fenómeno é constituída, sem dúvida, pelos acidentes de trabalho mortais, objeto de regular atenção pública e mediática. Os acidentes de trabalho não mortais, por sua vez, não obstante serem mais frequentes, tendem a 
caracterizar-se pela sua invisibilidade, a qual contribui para uma menor relevância dada à complexidade inerente às respetivas consequências e às vicissitudes do sistema legal de proteção. Neste âmbito, a dimensão institucional associada aos percursos póssinistro constituiu-se como elemento de análise e foi explorada no sentido da compreensão do modo como os sinistrados no trabalho se relacionam com o dispositivo legal e institucional previsto formalmente para a efetivação do direito à reparação. Esta dimensão foi introduzida no principal instrumento de recolha de informação deste projeto, o inquérito por questionário, cuja conceção e aplicação a 366 sócios e ex-sócios da ANDST foi antecedida pela realização de dez entrevistas aprofundadas pela e reconstituição das experiências dos sinistrados através da elaboração de dez mapas de percurso ${ }^{[2]}$. As entrevistas incidiram sobre três grandes grupos de questões: a caracterização socioprofissional, o acidente de trabalho e o percurso pós-sinistro. Em relação ao terceiro, aqui em análise, a abordagem dividiu-se na exploração de aspetos relativos aos contactos institucionais, por um lado, e aos contactos informais, por outro (respeitando o registo, para cada momento de contacto, das atividades, dos canais e interfaces, dos facilitadores e obstáculos encontrados, dos sentimentos experienciados, de sugestões de melhoria). Por sua vez, em traços gerais, o inquérito por questionário contempla a caracterização sociodemográfica e profissional, as circunstâncias e consequências do acidente de trabalho (ao nível laboral, da reparação legal, da saúde da imagem de si e relação com os outros) e o balanço do impacto do acidente na vida pessoal, familiar e social dos indivíduos.

2 O presente texto, após percorrer brevemente algumas referências teóricas que incidem a sua análise na relação dos indivíduos com as instâncias administrativas e burocráticas do Estado, fará uma incursão sintética no quadro regulatório em vigor dirigido aos acidentes de trabalho - particularmente sobre o conceito de acidente de trabalho, a responsabilidade, o risco e o dano -, para, posteriormente, tecer algumas considerações sobre as vicissitudes do mesmo e, à luz do material empírico recolhido, finalmente, refletir acerca dos percursos pós-sinistro vivenciados pelas vítimas de acidente de trabalho.

\section{Os percursos da relação dos indivíduos com as instituições: algumas referências teóricas}

3 Vários estudos a nível internacional vêm alertando, há várias décadas, para a dissociação entre, por um lado, os atos normativos e a sua fundamentação, as estruturas administrativas e as decisões políticas e, por outro, as práticas adotadas no quotidiano institucional (Crozier, 1964; Pressman \& Wildavski, 1973; Lipsky, 1980; entre outros).

4 Michael Lipsky, sociólogo norte-americano que rompe com as teorias clássicas da sociologia das instituições, apela, na sua obra Street-level Bureaucracy. Dilemmas of the Individual in Public Services (1980), para a importância da compreensão daquilo que separa as políticas públicas - no seu estado estático - como instrumentos regulativos da forma como os burocratas as acionam junto dos utentes que as experienciam nos serviços das instituições - de forma contextualizada e processual, interativa, relacional. É neste encontro de papéis que, segundo o autor, se pode chegar de forma mais objetiva ao entendimento do que são essas mesmas políticas públicas, sendo que o desenrolar do 
processo administrativo de aplicação das normas na linha da frente não pode ser ignorado se quisermos compreender os verdadeiros impactos das políticas públicas.

O interesse analítico por esta matéria tem vindo a ser reforçado mais recentemente, nomeadamente em França, por autores como Vincent Dubois, em La vie au guichet: relation administrative et traitement de la misère (1999) e Yasmine Siblot, em Faire valoir ses droits au quotidien. Les services publics dans les quartiers populaires(2006). Através de aproximações etnográficas à realidade das instituições públicas, estes autores centramse no exame dos encontros quotidianos que entre aquelas e os indivíduos que as procuram acontecem, para desse exame retirar ilações sociológicas relevantes sobre o panorama geral da relação entre Estado e cidadãos.

De acordo com Dubois (1999), que estudou os encontros quotidianos entre instituições do Estado Social e os respetivos utentes, dimensões como o controlo burocrático, a distância social, os processos de negociação (no caso de existirem), a dominação simbólica, entre outras, são de incidência analítica indispensável quando procuramos analisar os atendimentos administrativos e jurídicos, administrados precisamente por burocratas do Estado. Os indivíduos são colocados perante uma instituição que tem no seu poder a potencial resolução do problema que vivem, nomeadamente o poder de decidir questões relativas à distribuição dos recursos do Estado Social, e experienciam encontros caracterizados por uma opacidade administrativa, a existência de requisitos de conhecimento e de domínio de linguagem técnica.

7 Yasmine Siblot, investigadora que em França se debruçou sobre a relação das classes populares com os serviços públicos, revela que esta experiência de contacto com a burocracia do Estado não precisa de ser necessariamente - nem será, seguramente, em grande número de casos - uma relação estrita de dominação do 'aparelho estatal' (por via direta ou indireta) sobre aqueles que com ele interagem, uma relação que, portanto, nestes termos, seria necessariamente geradora de atrito, desinteligência e equívoco, traduzida ora em silêncio resignado, ora em revolta potencialmente geradora de dissensão. Na verdade, estamos perante formas de relação muito variadas, a cujas configurações e resultados não são alheias quer as formas como as instituições se organizam e apresentam na interação quotidiana com os seus utentes, quer os sistemas de disposições que confluem nos encontros mencionados, os capitais e as trajetórias prévias que lhes subjazem, as estratégias e as táticas mobilizadas pelas partes. Tratando-se, como é o caso, de instituições que acolhem utentes com origens, disposições, circunstâncias e trajetórias muito diversas - a realidade dos sinistros laborais apresenta padrões passíveis de identificação e explicação, mas não deixa de ser ampla e diversa -, ganha relevância o estudo dos encontros onde essa relação quotidianamente se concretiza, pois é neles e através deles que se constroem espaços de manobra ou, pelo contrário, se fecham oportunidades àquela afirmação de posições e efetivação de direitos.

\section{Notas sobre o risco, o dano e a responsabilidade na legislação portuguesa}

8 Em Portugal, durante o Século XIX, a única via que as vítimas de acidentes de trabalho tinham para eventualmente receber uma indemnização era a de tentar provar em tribunal a responsabilidade do empregador na ocorrência do desastre ${ }^{[3]}$, o que na prática se revelava quase impossível. Foi apenas a partir de $1913^{[4]}$ que a 
responsabilidade passou a ser objetivamente atribuída ao empregador, primeiro assente na doutrina do risco profissional e, a partir de 1936 até aos dias de hoje, na do risco económico ou de autoridade ${ }^{[5]}$, transferível para entidades seguradoras. As leis dos acidentes de trabalho foram, ao longo dos tempos, assumindo um leque mais vasto de conceções de risco, extravasando claramente a zona de riscos derivada da atividade laboral e abrangendo situações de risco geral, em que a entidade patronal deverá contribuir para uma vida digna do trabalhador, enquanto que este último contribuiu para a atividade do empregador.

9 Atualmente a transferência da responsabilidade para as seguradoras por parte dos empregadores é imperativa, sendo estas as entidades que atuam, em princípio, desde o início numa situação de acidente de trabalho. Este sistema de responsabilidade privada $^{[6]}$ - com introdução de uma entidade estranha à realidade laboral e às políticas sociais - não é dominante nos ordenamentos jurídicos europeus, onde a reparação dos acidentes de trabalho tende a assentar largamente num sistema de segurança social. Não foi apenas ao nível associativo e político que se observou contestação relativamente ao regime de responsabilidade na reparação dos acidentes de trabalho. Verifica-se na doutrina jurídica um vasto número de reflexões acerca desta matéria, que denunciam a inadequação deste sistema de responsabilidade, defendendo que um sistema de segurança social garantiria uma maior proteção ao trabalhador (Leitão, 2001). A responsabilização de particulares por um risco que é, na verdade, coletivo, social, deveria, segundo o autor, dar lugar a um esquema de seguro social a cargo da coletividade.

10 A Lei n.. 98/2009, atualmente em vigor, regulamenta o regime de reparaçãa ${ }^{[7]} \mathrm{de}$ acidentes de trabalho e de doenças profissionais ${ }^{[8]}$, incluindo a reabilitação e a reintegração profissionais, cujos princípios estão consagrados no Código do Trabalho de 2009. No que diz respeito ao conceito de acidente de trabalho, é possível identificar, através da definição do mesmo presente nesta Lei, os requisitos necessários para que um acidente seja enquadrado neste âmbito. Cumulativamente, i) é necessária a identificação de um acidente ii) que ocorra no local de trabalho, iii) no tempo de trabalho, iv) do qual resulte um dano, isto é, 'produz direta ou indiretamente lesão corporal, perturbação funcional ou doença, de que resulta redução na capacidade de trabalho ou de ganho ou a morte', v) sendo que deverá existir um nexo causal entre este último e o acidente ${ }^{[9]}$.

O núcleo essencial do conceito de dano prende-se com os casos em que há uma incapacidade ou nos casos de morte, ou seja, quando há um dano indemnizável, sendo que estamos perante uma tutela do direito à integridade económica ou produtiva do trabalhador - isto é, em que medida a sua capacidade de ganho para o seu trabalho habitual ou para qualquer outro trabalho foi afetada pela lesão. Esta 'conceção produtivista do trabalhador, que esgota a sua identidade na sua força de trabalho e o seu corpo na sua função instrumental' (Santos, Gomes \& Ribeiro, 2012: 232), separa o trabalhador do cidadão ao não contemplar a reparação de danos morais e psicológicos, ao nível sexual, estético, de afirmação pessoal e outros não patrimoniais, impossibilitando a satisfação de todos os interesses lesados na vida da vítima (Alegre, 2001). Para além disso, o facto de na base da reparação de uma perda de capacidade de ganho estar o critério salarial ${ }^{[10]}$ gera assimetrias evidentes e coloca os trabalhadores dos setores mais expostos aos riscos, que, por norma, auferem rendimentos mais baixos, perante uma potencial indemnização muito aquém dos prejuízos que 
efetivamente foram sofridos (Santos, Gomes \& Ribeiro, 2012). No quadro regulatório atual, os danos são 'reparados tendo em conta o «valor económico» da vítima, o que gera grandes injustiças sociais' (Magalhães \& Antunes, 2012: 286).

Por sua vez, a relação entre o acidente e a lesão é feita através do nexo de causalidade, o qual nem sempre é imediatamente identificado e é necessário fazer-se prova do mesmo, quando sobre este se colocam dúvidas. Ramalho (2006, p.739) chama a atenção para a complexidade do 'estabelecimento de nexo de causalidade entre o sinistro e as suas consequências', entre a acidente e o dano físico ou psíquico, e esse dano e o dano laboral (redução ou exclusão da capacidade de trabalho), sendo que a falta de qualquer destes elementos exclui o dever de reparação.

\section{Os percursos pós-sinistro: para além do guião de reparação institucional}

\subsection{Os contactos com o sistema de reparação em síntese}

13 Para se tornar possível a aproximação compreensiva do que, na prática, decorre dos instrumentos legais - a sua materialidade - procurou-se levar a cabo uma análise que não se esgotasse naquilo que é objetivo (legislação e regulação de procedimentos e processos judiciais), mas que procurou relevar igualmente os elementos subjetivos e aquilo que surge sob a forma de 'imprevisto'. Assim, e após a identificação da rede institucional, dos normativos jurídicos e dos procedimentos prescritos pelo Código de Processo de Trabalho (CPT) para a efetivação de direitos resultantes de acidente de trabalho no sentido de delinear o percurso legal que serve de orientação para as ações de todos os protagonistas envolvidos no processo, ainda numa fase exploratória, procurou-se, no presente estudo, chegar a esse nível de análise através da realização de entrevistas e da construção de mapas de percurso. Este instrumento permitiu registar não só os momentos de contacto institucional legalmente previstos (nomeadamente com o empregador, as seguradoras e o Tribunal do Trabalho), mas também, e porque o percurso pós-sinistro não se esgota nestes, os contactos (formais e até informais) que são ativados em paralelo, por se revelarem necessários e, por vezes, até decisivos.

Sendo a análise aqui levada a cabo dirigida aos momentos de contacto dos indivíduos com as instituições, apresentam-se de seguida, sem pretensão de esgotar os elementos de relevo presentes em ambos os documentos, os procederes de cariz obrigatório descritos no CPT e na Lei n.. 98/2009, que implicam momentos de contacto entre as vítimas de um acidente de trabalho não mortal e as instituições num percurso póssinistro.

15 Após a ocorrência do acidente, os sinistrados são assistidos no local onde o mesmo sucedeu e, nos casos que constituam urgência médica, devem ser transportados para o hospital, onde eventualmente podem ter que ficar internados. Caso o empregador não tenha presenciado ou não tenha tido conhecimento do acidente, o sinistrado deve fazer a respetiva participação. Por sua vez, a comunicação da ocorrência do acidente à seguradora constitui um dever do empregador. No caso de não ter procedido à transferência (obrigatória) da responsabilidade a uma seguradora, o empregador deve comunicar a ocorrência ao tribunal competente. Uma vez recebido o sinistrado, a seguradora deve prestar todos os tratamentos necessários à recuperação da lesão do sinistrado (nestes contactos se incluindo consultas de acompanhamento, avaliações de 
danos corporais/definição de incapacidades temporárias ou permanentes/atribuição do boletim de alta médica). Sob a alçada da seguradora, o sinistrado poderá receber a indicação de que deve regressar ao trabalho, com alta com ou sem desvalorização decorrente de uma incapacidade temporária, e, no caso duma cura clínica a $100 \%$, sem qualquer tipo de incapacidade (eventualmente após períodos com desvalorização), não é obrigatória a participação ao Tribunal do Trabalho por parte da seguradora (é facultativa para o sinistrado, se dela discordar $\left.{ }^{[11]}\right)$. Perante uma sucessão de incapacidades temporárias que ultrapassem 12 meses, ou a identificação de uma incapacidade permanente, a participação pela seguradora ao Tribunal do Trabalho é obrigatória, altura em que esta deve comunicar o grau de incapacidade permanente decorrente da sua avaliação de dano corporal.

o processo em tribunal responderá a uma estrutura bifásica, sendo a primeira fase, e de realização obrigatória, a conciliatória, dirigida pelo Ministério Público (MP) ${ }^{[12]}$. Este momento processual tem como finalidade a resolução amigável e conforme à lei, e implica três atos processuais: a instrução preliminar, a perícia médica suscitada pelo MP e levada a cabo pelo médico perito do Instituto Nacional de Medicina Legal (INML) e, por fim, a tentativa de conciliação. Se houver acordo entre as partes sobre os elementos em questão, e se o acordo for homologado pelo juiz, o processo termina. Caso não haja anuência, inicia-se a fase contenciosa, e se a ausência de consensos se referir, por exemplo, à incapacidade ${ }^{[13]}$, será convocada a Junta Médica. Esta é constituída por três peritos médicos, em representação do tribunal (nomeados pelo INML), do sinistrado (um médico da sua escolha ou um nomeado oficiosamente pelo tribunal), e da seguradora. Presidida por um juiz, esta fase termina com a sua decisão face aos elementos apresentados e defendidos pelas partes.

17 Serão apresentados, de seguida, alguns dos elementos ilustrativos dos percursos póssinistro, recolhidos da análise das entrevistas, dos mapas de percurso e do inquérito por questionário do projeto 'Regresso ao trabalho após acidente: superar obstáculos'.

\subsection{0 acidente e os impactos na esfera laboral}

18 A ocorrência do acidente de trabalho pode significar, em si, um acontecimento traumático na vida dos trabalhadores, cujos efeitos se tornam visíveis não só na forma como estes encaram o trabalho, mas também no modo como veem a vida em geral. 0 medo das consequências que o acidente de trabalho pode trazer para a capacidade de trabalho, ou até para a potencial empregabilidade futura do trabalhador, é transversal nos discursos dos entrevistados.

Verificou-se que, ainda que configure um cenário menos comum no seio das entrevistas realizadas a sócios e ex-sócios da ANDST, nem sempre a participação do acidente de trabalho ocorre de forma automática, sem resistências e obstáculos. 0 empregador, seja face ao desconhecimento em relação às normas acima descritas, ou à resistência em assumir que determinada ocorrência corresponde a um efetivo acidente de trabalho, nem sempre agiliza o processo com a devida urgência que o problema exige. A resolução deste impasse logo no arranque do sistema de reparação pode ter que passar por diligências levadas a cabo pelos sinistrados ${ }^{[14]}$, nomeadamente por aconselhamento legal e comunicações escritas a ambas as entidades - empregador e seguradora -, no sentido de se garantir o direito a tratamentos médicos. Na ausência da iniciativa do trabalhador em repor o sentido correto do início do percurso pós-sinistro, 
o acidente de trabalho não chega, na verdade oficial, a sê-lo, e com ele qualquer possibilidade de reparação médica a cargo das entidades responsáveis e a possibilidade de vir a ter direito a uma pensão resultante de um dano permanente. Segundo os testemunhos de elementos da ANDST estes casos são seguramente muitos e, por escaparem à tutela prevista do Estado e das entidades responsáveis, invisíveis. Este facto constitui um primeiro exemplo de como, tanto a postura imediata de apoio do empregador perante o trabalhador, como um eventual processo de responsabilização e acompanhamento durante todo o processo, são descritos pelos entrevistados como determinantes para um percurso pós-sinistro vivido.

20 A centralidade dos discursos sobre os percursos reside no processo de retorno ao trabalho. E ainda que a maioria dos entrevistados viva esse regresso, este não significa, muitas vezes, que se vá encontrar no universo laboral um cenário igual àquele que se deixou quando se iniciou o percurso pós-sinistro, como se o momento anterior ao acidente tivesse ficado à espera, congelado, pelo regresso do trabalhador. Quando a capacidade do trabalhador para o desempenho das funções deixa de ser a mesma - e não há da parte do empregador intenção de adaptar o posto de trabalho, questão que, de resto, está prevista na legislação em vigor -, o regresso ao trabalho pode constituir um processo muito doloroso para o trabalhador e acabar mesmo por resultar em despedimento:

21 '(...) eu entro para aqui em condições, passado um mês tenho acidente, vêm-me dizer que a máquina onde me aleijei já está nova, alterada com proteção, e passado uma semana [depois de dar formação a outra pessoa para a função] mandam-me embora: «nós não temos mais trabalho para si» (...) E agora sem saber se vou arranjar emprego... assim com a mão...' (Serralheiro, 48 anos, lesão na mão)

Um dos principais impactos do acidente na esfera laboral verifica-se no rendimento mensal dos sinistrados, tanto em termos de quantidade, quanto de modalidade. Conforme assinala Madureira Pinto (2017, p.5), 'Dada a simples passagem do tempo de recuperação física dos sinistrados, a que acrescem dificuldades de relacionamento com a malha jurídico-institucional prevista para reparar as consequências do acidente, traz consigo um forte potencial de desactivação, a adaptação à nova condição faz-se sob a ameaça de uma efetiva erosão de direitos e rendimentos'. De acordo com os dados recolhidos no projeto da ANDST, antes da ocorrência do acidente de trabalho, a principal fonte de rendimento dos sinistrados era, para 82\%, o salário. Após o acidente, essa percentagem desce para 46,4 . Por sua vez, entre estes dois períodos considerados, observa-se um aumento da percentagem de sinistrados que vivem principalmente de prestações sociais (2,5 para $25,1 \%)$, significando uma 'transição forçada da condição de assalariado para a de beneficiário' (Pinto, 2017, p.5). E mesmo para aqueles que conservam o emprego, verifica-se não só uma diminuição dos complementos remuneratórios, como uma tendência para a precarização do estatuto socioprofissional[15], condições que concorrem para um processo gradual de deterioração do nível de vida que os trabalhadores viviam antes da ocorrência do sinistro.

Muitos outros elementos fazem parte do universo de impactos que um sinistro laboral transporta consigo para as mais diversas dimensões da vida dos trabalhadores. E ainda que um exercício mais completo a este nível não seja aqui exequível, é de todo pertinente sublinhar os elementos de síntese que Pinto (2017, p.4 e p.5) dirige ao conjunto de efeitos decorrentes deste flagelo: a existência de uma 'dupla precarização 
da condição profissional', que decorre da análise da relação com o trabalho e da relação com o emprego; e a existência de processos de 'restruturação identitária' decorrentes da vivência de um percurso pós-sinistro que implica, não raras vezes, uma dramática descontinuidade na vida profissional e, por extensão, nas restantes dimensões de existência das vítimas, sendo esta uma 'ilustração particularmente expressiva, pela negativa, da centralidade social das relações de trabalho':

'Também há a parte que não tem a ver com o dinheiro. Interiormente, uma pessoa sente-se mais diminuída, eu não andava assim, percebe? Eu não tinha as limitações que tenho hoje, não mancava, conseguia andar direito, não tinha que descansar, e isso afeta-nos também. (...) e já não basta o facto de uma pessoa estar parada, estar obrigada a estar em casa, uma pessoa fica mais isolada (...) uma pessoa fica completamente sozinha. Houve muita coisa na minha vida que modificou. (...). Antigamente uma pessoa estava habituada a levantar, tomar banho, vestir e ir trabalhar... agora acabou. (...) Adoro praia, fui criado praticamente na praia, e agora não consigo andar na areia. São coisas que marcam, que realmente marcam bastante, mas tenta-se não pensar nisso (...). Enquanto uma pessoa trabalha tem qualidade de vida, mantemos o nosso estatuto social... acontece uma coisa destas e isso deixa de acontecer. Já tenho reparado em algumas situações e antes quase que nem estava atento a esse tipo de situações, há pessoas que perdem isso tudo. E isso o que é que provoca em mim? Provoca-me receio, ansiedade'. (Chefe de cozinha, 52 anos, lesão na coluna e na perna)

\subsection{O contacto com a seguradora}

A relação estabelecida no contacto direto com os médicos das seguradoras, e apesar das circunstâncias negativas associadas a uma ocorrência deste tipo, pode constituir uma experiência positiva. É assim reportada para uma parte, ainda que reduzida, dos entrevistados, que destacam, por um lado, o relacionamento interpessoal com o médico assistente, caracterizado por uma postura de proximidade, com abertura ao diálogo e, por outro, a componente clínica em geral (acompanhamento, tratamentos, medicação). Por sua vez, uma avaliação negativa da relação com as seguradoras está associada a vários fatores que, em muitos casos, se conjugam cumulativamente. Um dos fatores largamente destacado prende-se com a discursividade empregue pelos médicos, que parece evidenciar uma intencionalidade na manutenção não só de uma distância interpessoal, como também de uma distinção de ordem técnica e linguística. Adicionalmente, nestes momentos de contacto, o diagnóstico - que condicionará o acompanhamento que se lhe segue - pode constituir igualmente um momento de grande tensão. A este momento de receção do indivíduo na instituição é associada imprecisão em relação à avaliação inicial, que é várias vezes relatada como sendo um sério obstáculo à reabilitação física e até à reparação legal (no que diz respeito à atribuição de uma pensão decorrente da definição de uma incapacidade). Muitas vezes, nestas situações, verifica-se a sugestão, por parte do médico, de que a lesão se reporta não ao acidente de trabalho, mas a um problema de saúde pré-existente, a uma doença natural, ou até à idade avançada do sinistrado:

'A sensação que eu tenho é que és velhinha, vais para casa, tens uma reforma da banca, e vai-te embora. Portanto, eu estou a ser avaliada dessa forma. (...) Estou a trabalhar na loja de decoração e estou a receber uma reforma, mas não interessa, não interessa. Um acidente é um acidente e a empresa paga precisamente para cobrir estas coisas. Não é pelo facto de eu já ser uma pessoa de idade e já ter uma reforma. (...) Fiquei um bocado, não vou agora dramatizar, é 
assim, mas confesso que não gostei de ser tratada pela companhia de seguros, muito menos por um médico da forma como fui. Fiquei muito desagradada, é como lhe digo, na altura manifesteime, deitei cá para fora aquilo que sentia. Estou velha, estou reformada, vai para casa, não vale a pena investir em ti. Foi isso que senti'. (Vendedora numa loja de antiguidades, lesão na coluna, 69 anos)

A utilização de um discurso evasivo, a prescrição de medicação forte para atenuar os sintomas, a resistência na prescrição e exames para melhor diagnóstico caracterizam uma intervenção médica que, na perspetiva dos sinistrados, parece procurar evitar um diagnóstico apurado, que implicaria outro tipo de tratamentos e, consequentemente, mais custos para a seguradora. A sensação de impotência perante a discrepância entre as decisões médicas e o problema de saúde que se faz sentir (onde se crê que haja imprecisão no diagnóstico e pouca importância dada a determinados sintomas), introduz, nalguns percursos, o recurso a médicos particulares. Isto constitui, na perspetiva dos sinistrados, a procura de uma figura imparcial que auxilie no processo de decifrar qual é, afinal, a condição médica real do sinistrado e os tratamentos possíveis para o caso concreto. Dos casos observados, nenhuma destas diligências, fosse no sentido da realização de uma intervenção cirúrgica, ou da continuidade de tratamentos interrompidos pela seguradora, resultou numa alteração da decisão já tomada por parte desta última. Não é apenas nesses contactos de recurso estabelecidos por iniciativa do sinistrado que são confirmadas, muitas vezes, lesões mais graves do que as identificadas na avaliação médica da seguradora, mas também no momento da perícia médica no INML.

28 O momento da alta clínica é um marco particularmente sensível do percurso póssinistro. Se, até então, a dúvida em relação à eficácia dos tratamentos, ao facto de se conseguir voltar a trabalhar ou não, já é evidente, no momento da alta clínica toda uma sensação de incerteza e dúvida se agudiza. Este é descrito como sendo uma consulta rápida feita por um 'perito da seguradora', caracterizada por diálogos curtos, dotados de poucos esclarecimentos, e em que se comunica o reconhecimento da existência de uma incapacidade parcial permanente - e consequente seguimento do processo para o tribunal do trabalho -, ou a avaliação de uma cura clínica a 100\%. Em ambos os casos, é dada alta médica, o que implica que o trabalhador deve regressar às suas funções. Nos casos em que o trabalhador não se encontra em condições de saúde para retomar as suas funções, e enquanto o processo em tribunal não decide a natureza da incapacidade, o recurso ao médico de família torna-se incontornável, pois, sem uma baixa médica, o sinistrado começa a efetivamente faltar ao trabalho. Há, no entanto, quem regresse ao trabalho nessas condições e viva dificuldades relativas ao desempenho das funções, conforme foi exposto acima no ponto sobre os impactos decorrentes de um acidente de trabalho.

Por sua vez, nos casos em que a seguradora avalia uma cura clínica a 100\%, portanto, sem qualquer tipo de incapacidade irremediável, a participação ao tribunal do trabalho, por não ser obrigatória para esta instituição, apenas ocorre quando o sinistrado dela discorda e tem conhecimento de que o pode fazer. Por falta de informação, muitos trabalhadores acabam por voltar ao trabalho com dores e limitações, sem recorrerem ao tribunal do trabalho para a procura da reparação legal na sequência do acidente de trabalho: do que o outro médico [assistente] me tinha dito [que me ia ser comunicada uma incapacidade], 
e ele disse-me: "Isso agora vai ficar com um relógio, mas sabe, também é a idade, os nossos ossos vão-se desgastando", e deu-me capacidade a 100\%. E pronto, eu lá fui, com muito esforço todos os dias e lá continuei a trabalhar. Enquanto eu andei na fisioterapia (...) andava lá uma senhora (...) que me perguntou: «Então, como é que está?». "Continuo com dores, mas olhe, que remédio, vou ficar com elas para toda a vida». «E você não recebeu nada nem foi ao Tribunal do Trabalho? (...) Tu tens direito». E eu: "Não, o outro médico [assistente] tinha dito que eu ia ficar com uma incapacidade, mas este [médico responsável pela alta] não me deu incapacidade nenhuma». E ela disse-me que tinha um ano para recorrer ao tribunal do trabalho. E faltavam muitos pouco dias!' (Auxiliar de ação direta, 61 anos, lesão nos membros superiores).

\subsection{0 contacto com o tribunal}

31 Regra geral, o primeiro momento de contacto com o tribunal após a alta clínica dada pela seguradora é a perícia médica solicitada pelo MP e realizada no INML, da qual resultará um coeficiente de incapacidade permanente que será um dos elementos base a ser alvo de aceitação ou não tanto por parte do sinistrado como da seguradora. Este encontro é descrito, muitas vezes, como sendo de duração relativamente rápida, onde o sinistrado deve relatar a ocorrência do acidente de trabalho, os sintomas que se mantêm e as consequências para a sua saúde e capacidade de trabalho. Ainda que tenham sido reportadas pelos sinistrados posturas distantes e impessoais por parte dos peritos, aquilo que mais causa impacto nestes encontros é a constatação de um grau de incapacidade superior ao proposto pela seguradora, a qual reforça ainda mais a sensação de injustiça presente nos contactos com a seguradora.

A procura de acordo entre as partes é conduzida pelo MP durante a fase conciliatória. Contudo, segundo a quase totalidade dos entrevistados, a figura do procurador está ausente. Os testemunhos dos sinistrados revelam que é o funcionário do tribunal (muitas vezes o único funcionário do Estado em todo o processo com quem lidam, para além do perito do INML) a figura principal de mediação nesta fase.

Perante a inexistência de acordo entre as partes, iniciar-se-á a fase do contencioso que, em muitos casos, quando as divergências dizem respeito ao grau de incapacidade, começará pela realização de um exame por junta médica. A presença do juiz nessa diligência, apesar de estar previsto no CPT que deverá presidir à reunião de deliberação da junta, é raramente identificada pelos sinistrados. E à semelhança da experiência que já traziam das seguradoras, a distância, impessoalidade e frieza são elementos muitas vezes mencionados pelos sinistrados no contacto com o tribunal e com os respetivos intervenientes nas diligências.

Pelo facto de o acompanhamento por um médico particular num exame de junta médica implicar custos, que nem sempre podem ser suportados pelos sinistrados, o mais comum é o tribunal nomear um médico que represente a vítima. 0 depoimento que se segue ilustra a opacidade e a tensão inscritas neste processo:

'Aqui há uma falta de informação muito grande, as pessoas que estão no tribunal não tratam as pessoas convenientemente, não dão informação. Quer dizer, de que é que nos serve o ministério público, se temos lá [junta médica] alguém, um médico a nos representar, quando não conseguimos levar ninguém, que nem sequer fala connosco? São incapazes de dizer assim: 'Olhe, eu represento o ministério público e vou defendê-lo. Qual é a situação?', ou dizer alguma coisa, mas não. Quer dizer, gasto eu uma pipa de massa em relatórios médicos para levar à junta médica e não têm valor nenhum, por aquilo que eu vejo. o trabalho que o doutor [nome do 
médico particular] fez, foi pelo cano abaixo (...). É claro que uma pessoa que está ali está um bocado menos à vontade, e por estar menos à vontade é também porque leva relatório complementares, para que nada falhe. Mas na ideia deles, os relatórios, aquilo é tudo uma mentira, como se estivéssemos a pagar para escreverem aquilo. Enfim. (...) Eles ficam lá dentro fechados, porque não permitem que uma pessoa ouça, temos que sair. Ao menos davam uma satisfação, mas isto passa-se tudo assim, uma pessoa entra, o que é que faz, mostro, vê, agora, não se preocupam, são objetivos, assertivos, mas não vão ver as limitações que uma pessoa tem, não se importam com nada disso. É assim, aquilo é uma bandalheira total'. (chefe de cozinha, 54 anos, lesão na coluna e na perna)

\subsection{Outros contactos institucionais e informais da iniciativa do sinistrado}

Através do material empírico recolhido nas entrevistas foi possível registar, para além dos momentos de contacto institucional legalmente previstos, e porque o percurso póssinistro não se esgota nestes, os contactos (formais e até informais) que são ativados em paralelo, por se revelarem necessários e, por vezes, até decisivos. Os dados obtidos através de inquérito por questionário do projeto da ANDST vão no mesmo sentido, ao indicarem uma tendência para a identificação de apoio por parte não (só) das entidades que fazem parte do guião institucional da reparação em caso de acidente de trabalho, mas principalmente daquelas às quais recorreram por iniciativa própria: destacam-se os «familiares, amigos e conhecidos» (49,8\%) e a «ANDST ou outra associação» (36,9\%); em sentido oposto, a entidade que mais se evidencia com uma avaliação negativa dos momentos de contacto é a seguradora (20,3\%).

Perante obstáculos como a tentativa de desresponsabilização, ora da entidade patronal, ao resistir a participar o acidente à seguradora, ora da seguradora, ao resistir em reconhecer o nexo causal entre a lesão e o acidente (reportando, por exemplo, para uma doença natural ou para a idade avançada), os sinistrados procuram apoio na sua rede de conhecimentos, na ANDST, e junto de profissionais médicos fora da alçada das seguradoras (de família ou particulares). Por outro lado, há sinistrados que, ao não terem efetivamente condições de saúde para regressarem ao trabalho (apesar da alta clínica dada pela seguradora), solicitam apoio à ANDST (nomeadamente perante a recusa da entidade empregadora em aceitar o trabalhador de volta, ou em adaptar as funções às limitações do mesmo, ou ainda para a participação do acidente ao Tribunal do Trabalho), e ao médico de família (para obtenção de baixa médica através da Segurança Social). A preocupação em voltar a trabalhar é central nos discursos. Estes recursos, aos quais se podem juntar os advogados e o sindicato, vão no sentido, tantas vezes, de procurar garantir um desfecho justo, que não lhes parece ser possível quando dependem apenas de si mesmos.

\section{Reflexões finais}

38 A diversidade de pontos de partida é ampla. Para esta contribuem as características socioprofissionais, a idade, o género, a escolaridade, o percurso profissional, a profissão atual, a relação contratual, a exposição ao risco, etc., às quais se juntam as circunstâncias, consequências e limitações decorrentes do sinistro. Inicia-se, assim, um percurso de contacto com instituições que, na maioria dos casos, são estranhas aos 
indivíduos e que se regem por princípios e normas que estes desconhecem. 0 trajeto formal pós-sinistro está previamente traçado nos imperativos normativos, no entanto, os sinistrados percorrem-no não raras vezes quase às escuras, decifrando os meandros dos procedimentos conducentes à reparação legal por vias paralelas a este guião.

o sinistrado parece atravessar o seu percurso pós-sinistro, muito frequentemente, como um peão que vive processos de fragilização a vários níveis nesta trajetória de contactos com as instituições: fragilização física, desde logo, fragilização psicológica e identitária, vulnerabilidade perante o mercado de trabalho, ausência de conhecimento sobre o modo de funcionamento das instituições, e falta de um acompanhamento que possa, de certa forma, exercer controlo no processo de efetivação dos direitos referentes à reparação legal na sequência de um acidente de trabalho. Verifica-se a inexistência de uma instituição de tutela pública que atue, de forma sustentada, no sentido do acompanhamento de todo do processo (em certa medida, acontece, por exemplo, na Bélgica, com o Fundo de Acidentes de Trabalho). A desvantagem de partida do sinistrado é, desde logo, assinalada nos documentos jurídicos e processuais, ao sublinharem a relação assimétrica jurídico-laboral inerente à condição de trabalhador subordinado, que é, de resto, acentuada perante todas as fragilidades que um acidente de trabalho comporta. No entanto, a mediação prevista para o Estado no sentido de ajustar o equilíbrio no processo de reparação em questão não parece ser tão consistente quanto seria de esperar. Conforme especificam Santos, Gomes e Ribeiro (2012, p. 242): 'de um lado, o sinistrado com todas as fragilidades da sua circunstância social e pessoal; do outro, o poder de um grande grupo económico', isto é, a seguradora. Verifica-se, também, o carácter contingente das formulações estruturais, que tendem a não ser independentes das ações individuais, tanto dos sinistrados, como dos representantes das instituições. A atuação não consistente do tribunal e das seguradoras, lida na distinção entre a descrição formal do seu papel e a prática quotidiana, é reveladora disso mesmo. 0 primeiro medeia a tentativa de conciliação e patrocina o sinistrado no processo judicial, responsabilidades que revelam a elevada importância do MP na garantia da efetivação de direitos do sinistrado. No entanto, são raros os testemunhos que os colocam presencialmente nessas situações, denunciando a existência dessa incongruência. Verifica-se, no mínimo, uma relativa demissão do tribunal na relação próxima com os sinistrados. Estas situações, onde não só as condições práticas da realização das diligências são afetadas, como também o são as condições simbólicas (Siblot, 2006), contribuem para a formatação da visão que os indivíduos têm do Estado (Dubois, 2014). Esta situação de dependência estrutural do indivíduo em relação à máquina administrativa das instituições desemboca em encontros estruturalmente assimétricos (Lipsky, 1980).

O sinistrado poderá, eventualmente, tomar a iniciativa de procurar esclarecimentos sobre os seus direitos e pedir aconselhamento, por exemplo, a entidades como a Autoridade para as Condições do Trabalho, ao MP ou, eventualmente, consultar um advogado; no entanto, em muitos casos, não é nessas diligências individuais que se pode depositar o acompanhamento do sinistrado ao longo do seu percurso pós-sinistro, desde logo porque a efetivação de tais diligências está condicionada por diversos fatores, nomeadamente os que se relacionam com os capitais económicos e escolares dos indivíduos, a falta de informação prestada no que diz respeito a esta matéria, ou o distanciamento da população em relação ao tribunal e a outras instituições. Destaca-se, aqui, o papel da ANDST, ator satélite neste dispositivo, que parece estar a preencher 
uma lacuna séria existente num sistema legal de proteção social que parece deixar-se permear por elementos que contribuem para a reprodução das desigualdades sociais. De resto, não será demais lembrar que estes testemunhos se reportam apenas a sócios e ex-sócios da ANDST, que através desta beneficiaram de um acompanhamento relevante no seu percurso pós-sinistro, configurando-se frequentemente na reivindicação e garantia de direitos barrados noutras instâncias, e que estes representam uma pequena parte do universo de sinistrados em Portugal.

41 A classificação do acidente de trabalho como processo especial e urgente (conforme CPT) relaciona-se, entre outras coisas, com a constatação da assimetria da relação jurídico-laboral em que o trabalhador se encontra, recaindo o ónus da iniciativa processual não sobre os sinistrados, que poderiam abdicar dos seus direitos perante constrangimentos de terceiros, mas nas entidades responsáveis (Monteiro, 2011). No entanto, este efetivo controlo - na ausência de diligências por iniciativa própria (ou denúncias feitas por terceiros) em fases anteriores - só se inicia com a comunicação ao Tribunal do Trabalho. E se na relação laboral o trabalhador é considerado juridicamente a figura mais fraca, numa situação de acidente de trabalho, o desequilíbrio entre $\mathrm{o}$ indivíduo $\mathrm{e}$ as instituições acentua-se perante todas as fragilidades que a mesma comporta. Uma das reflexões que Madureira Pinto (2017, p. 5) apresenta sobre esta matéria, ao procurar analisar a centralidade do trabalho e a fratura identitária provocada pelos acidentes de trabalho, incide precisamente sobre a forma como a desestruturação causada por estes parece não encontrar no âmbito institucional de reparação uma estrutura de suporte:

42 [A] rutura decorrente do acidente torna-se, aliás, tão mais violenta, quanto mais a separação face ao quadro técnico-organizacional do trabalho for prolongada, no processo de tentativa de reparação por via jurídico-administrativa dos prejuízos causados pelo acidente, por um relacionamento com a lei e com as instituições envolvidas (serviços do Estado, tribunais, seguradoras) recheado de atritos, dilações e opacidades. À familiaridade com o local de trabalho - nem sempre gratificante, mas previsível - sucede, abruptamente, a incerteza, vivida frequentemente como opressivo arbitrário institucional, de um labirinto de normas e procedimentos com o qual as vítimas do acidente têm de aprender a lidar, sob pena de serem objeto de uma segunda exclusão social.

43 A evolução do dispositivo legal do acesso à reparação da sequência de um acidente de trabalho não foi, por sua vez, permeável nem às tentativas de reformulação de fundo, nomeadamente em relação ao sistema de responsabilidade privado vigente, levadas a cabo no meio associativo, em particular pela ANDST, político e jurídico, nem aos exemplos da grande maioria dos restantes países europeus, que apostaram num esquema de seguro social a cargo da coletividade (em concorrência ou não com esquemas privados), que, de resto, já acontece em Portugal com o regime legal de reparação dirigido a doenças profissionais.

Entre a manutenção deste regime e a sua substituição pelo regime de responsabilidade social, parecem estar, frente a frente, limitações a diversos níveis. De um lado, os constrangimentos orçamentais da segurança social, a excessiva burocratização que revestiria o processo e a força exercida pelas seguradoras em sede legislativa. Do outro, a inexistência de uma instituição de tutela pública transversal a todo o processo (que acompanhe, de forma automática, todos os passos necessários à efetivação dos direitos, mesmo quando sob a alçada de uma instituição de domínio privado) e as vicissitudes da 
gestão isolada por parte das seguradoras até à eventual participação ao Tribunal do Trabalho (continuando a interferir, a partir daí, por poder discordar da avaliação do INML e interferir na decisão em sede de exame por junta médica). Não assumindo que um sistema de reparação com base no sistema de segurança social corrigisse de forma automática muitos dos problemas que se registam no quadro atual, não pode deixar de se colocar em consideração, para além de todas as questões de subjetividade assentes numa avaliação de dano corporal, as fragilidades do sistema atual ${ }^{[16]}$.

\section{BIBLIOGRAFIA}

Alegre, C. (2001). Regime Jurídico dos Acidentes de Trabalho e das Doenças Profissionais.

Coimbra: Almedina (2 $2^{\mathrm{a}}$ Ed.).

Autoridade para as Condições do Trabalho (2017). Promoção da Segurança e Saúde no Trabalho em 2016. Relatório de atividades apresentado à Assembleia da República. DSPSST - Direção de Serviços para a Promoção da Segurança e Saúde no Trabalho (Coord.). Lisboa: ACT.

Crozier, M. (1964). Bureaucratic Phenomenon: an examination of bureaucracy in modern organizations and its cultural setting in France. University of Chicago Press.

Dubois, V. (1999). La vie au guichet. Relation administrative et traitement de la misère. Paris: Economica.

Dubois, V. (2014). The State, Legal Rigor, and the Poor. The Daily Practice of Welfare Control. Social Analysis, 58 (3), 38-55.

Goffman, E. (1983). The Interaction Order. American Sociological Review, 48, 1-17. https:// doi.org/10.2307/2095141

Leitão, L. (2001). A Reparação de danos emergentes de acidentes de trabalho. In Pedro Romano Martinez (Coord.). Estudos do

Instituto de Direito do Trabalho (pp. 538-579). Coimbra: Almedina.

Lipsky, M. (1980). Street-level Bureaucracy. Dilemas of the individual in public services. New York: Russel Sage Foundation.

Magalhães, T., \& Antunes, I. (2012). Acidentes de trabalho. Avaliação médico-legal dos danos na pessoa. In H. V. Neto; J. Aresosa; P. Azeres (Eds.). Impacto social dos acidentes de trabalho (pp. 266-287). Vila do Conde: Civeri Publishing.

Magalhães, T., Antunes, I., \& Vieira, D. N. (2009). A avaliação do dano na pessoa no âmbito dos acidentes de trabalho e a nova tabela de incapacidades. Prontuário de Direito do Trabalho Centro de Estudos Judiciários, 83, 147-170.

Monteiro, J. (2011). Fase conciliatória do processo para a efetivação de direitos resultantes de acidente de trabalho: enquadramento e tramitação. Prontuário de Direito do Trabalho - Centro de Estudos Judiciários, 87, 124-135.

Pinto, J. (1996). Contributos para uma análise dos acidentes de trabalho na construção civil. Cadernos de Ciências Sociais, 15-16, 86-119. 
Pinto, J. (2017). Impactos do acidente sobre a vida profissional: rendimentos, emprego e relações de trabalho. Le Monde Diplomatique - Edição Portuguesa, n.ำ 127, pp. 4-5 (Dossier O acidente de trabalho não é o fim da história).

Pressman, J. L., \& Wildavsky, A. (1973). Implementation. Berkeley: University of California Press. Ramalho, M. R. (2006). Direito do Trabalho, Parte II - Situações Laborais Individuais. Coimbra: Almedina.

Ribeiro, V. (1984). Acidentes de Trabalho: Reflexões e notas práticas. Lisboa: Rei dos Livros. Santos, B. S., Gomes, C., \& Ribeiro, T. (2012). Os acidentes de trabalho nos tribunais portugueses. In H. V. Neto; J. Areosa;

P. Arezes (Eds.), Impacto Social dos Acidentes de Trabalho (pp. 228-264). Vila do Conde: Civeri Publishing.

Siblot, Y. (2006). Faire valoir ses droits au quotidien. Les services publics dans les quartiers populaires. Paris: Presses de Sciences Po.

Weber, M. (1968). Economy and Society. New York: Bedminster Press.

Weller, J.-M. (1999). L'état au guichet: sociologie cognitive du travail et modernisation administrative des services publics. Paris: Desclée de Brouwer.

\section{NOTAS}

1. Projeto de investigação promovido pela ANDST e financiado pelo Instituto Nacional para a Reabilitação, I. P. (INR), que contou com uma equipa multidisciplinar de investigadores na área da sociologia e da psicologia.

2. Sobre a elaboração dos mapas de percurso, ver, neste número, Pereira e Rodrigues, 'A reconstituição de experiências após um acidente de trabalho: mapas de percurso como instrumento de análise'.

3. Artigo 2398. do Código Civil de 1867.

4. Lei n. .83 , de 24 de julho de 1913.

5. Lei n. ${ }^{\circ}$ 1942, de 17 de julho de 1936.

6. Os sistemas de responsabilidade de reparação de danos emergentes de acidentes de trabalho podem agrupar-se em três grandes grupos: sistemas de responsabilidade privada; sistemas de responsabilidade social e sistemas mistos (Ribeiro, 1984).

7. Art. 23..: 'O direito à reparação compreende as seguintes prestações: a) Em espécie prestações de natureza médica, cirúrgica, farmacêutica, hospitalar e quaisquer outras, seja qual for a sua forma, desde que necessárias e adequadas ao restabelecimento do estado de saúde e da capacidade de trabalho ou de ganho do sinistrado e à sua recuperação para a vida activa; b) Em dinheiro - indemnizações,_pensões, prestações e subsídios previstos na presente lei'.

8. 0 n. 2 do art.. 1.․ instrui que as doenças profissionais sejam regidas pelas mesmas regras que norteiam os acidentes de trabalho, com as necessárias adaptações e, subsidiariamente, pelo regime geral da segurança social.

9. Art.. 8., n.. 1 : 'É acidente de trabalho aquele que se verifique no local e no tempo de trabalho e produza directa ou indirectamente lesão corporal, perturbação funcional ou doença de que resulte redução na capacidade de trabalho ou de ganho ou a morte'.

10. Ao contrário do que acontece, por exemplo, nos países anglo-saxónicos, em que a reparação é efetuada in concreto (Magalhães, Antunes \& Vieira, 2009). 
11. A lei confere igual faculdade de participação do acidente de trabalho ao tribunal ao sinistrado, diretamente ou por interposta pessoa, aos familiares ou equiparados, a autoridades policiais ou administrativas que tenham tido conhecimento do mesmo, ao diretor do estabelecimento hospitalar, assistencial ou prisional onde tenha ocorrido o internamento, de forma a potenciar o exercício dos direitos fundamentais em questão.

12. Pode ler-se, no ponto 4 do preâmbulo do CPT: 'Quanto ao processo especial emergente de acidente de trabalho e de doença profissional e respectivos incidentes, as modificações operadas destinam-se, em primeiro lugar, a regular com maior precisão e apuro técnico e de modo mais completo alguns aspectos da sua peculiar tramitação, nomeadamente quanto ao modo de exercício das funções do Ministério Público, a quem incumbe a direcção da fase conciliatória, e cuja omissão a experiência mostrou ser causadora de embaraços e bloqueios prejudiciais à rápida definição dos direitos e obrigações emergentes de sinistros do trabalho, área em que, mais do que em nenhuma outra, se torna urgente aquela definição, tanto mais que a lei impõe que ela se faça sempre pela via judicial, em homenagem aos valores de interesse e ordem pública envolvidos'.

13. A fixação da incapacidade constitui o primeiro grande motivo de conflito e que resulta na grande maioria das ações em fase contenciosa, facto que evidencia a forte preponderância dos coeficientes de incapacidade no processo de reparação do sinistrado (vd. Santos, Gomes \& Ribeiro, 2012).

14. A lei confere igual faculdade de participação do acidente de trabalho ao tribunal ao sinistrado, diretamente ou por interposta pessoa, aos familiares ou equiparados, a autoridades policiais ou administrativas que tenham tido conhecimento do mesmo, ao diretor do estabelecimento hospitalar, assistencial ou prisional onde tenha ocorrido o internamento, de forma a potenciar o exercício dos direitos fundamentais em questão.

15. Através da relação entre as posições hierárquicas anteriores e posteriores ao acidente de trabalho dos indivíduos que responderam ao inquérito por questionário, pode recolher-se pistas concretas sobre os processos de desqualificação: dos 16 indivíduos com cargos de direção e gerência, apenas 8 os conservaram, um passou a encarregado geral, outro a trabalhador com autonomia, sem lugar de chefia; dos 21 indivíduos com carga de chefia direta/primeira chefia, apenas 9 mantiveram essa posição após ao acidente de trabalho, sendo que 2 deles passaram a executantes e 1 a trabalhador com autonomia, sem lugar de chefia. A par destes processos de mudança negativa, somam-se as situações de desemprego, situações de invalidez, de reforma antecipada e de incapacidade para trabalhar.

16. Dando continuidade à temática no seguimento da participação neste projeto, e no âmbito da dissertação de mestrado, desenvolvi uma investigação que problematiza sociologicamente as relações entre os indivíduos e as instituições, com um enfoque nas interações que decorrem nos encontros dos percursos pós-sinistro, cruzando os modos de funcionamento das instituições e o modo como a ordem social se produz e reproduz em contextos de interação dos indivíduos com as estruturas institucionais, a qual será, oportunamente, alvo de publicação de reflexões e resultados.

\section{RESUMOS}

O presente texto procura dar destaque à dimensão institucional como componente de análise no âmbito do projeto 'Regresso ao trabalho após acidente: superar obstáculos', da Associação Nacional de Deficientes Sinistrados no Trabalho (ANDST). Através da leitura cruzada de 
documentos jurídicos e administrativos, doutrina jurídica, dados do inquérito por questionário e dos testemunhos recolhidos em entrevista e compilados em mapas de percurso, procurou-se sistematizar os principais momentos que constituem um percurso pós-sinistro, reconstituindo não apenas o guião do percurso institucional de reparação, mas articulando-o com as representações dos sinistrados e com os obstáculos com que se deparam.

Este texto intenta subrayar la dimensión institucional como componente del análisis central en el marco del proyecto 'Regreso al trabajo tras accidente: superar obstáculos', de la Associação Nacional de Deficientes Sinistrados no Trabalho (ANDST). A través de la lectura cruzada de documentos jurídicos y administrativos, de la doctrina jurídica, de datos de la encuesta por cuestionario y de los testimonios recogidos en entrevista y compilados en mapas de trayecto se procuró sistematizar los principales momentos que constituyen un trayecto post-accidente, reconstituyendo no sólo la guía de trayecto institucional de reparación, sino también las representaciones de las personas accidentadas y los obstáculos a los que se enfrentan.

L'article veut souligner la dimension institutionnelle en tant que composante de l'analyse menée à la suite du projet "Retour au travail après un accident : surmonter les obstacles » de l'Association Nationale des Personnes Handicapées par un Accident de Travail (Associação Nacional de Sinistrados no Trabalho - ANDST). Grâce à une lecture croisée de documents juridiques et administratifs, de la doctrine juridique, des données d'une enquête par questionnaire et de témoignages recueillis par la voie d'entretiens, et convertis ensuite en cartes de parcours, nous avons systématisé les principales étapes du parcours post-accident. Cela a permis non seulement de reconstituer le parcours institutionnel de la réparation, mais également de l'articuler avec les représentations des accidentés et les obstacles que ceux-ci rencontrent.

The present paper seeks to highlight the institutional dimension of the analysis that was developed within the research project 'Return to Work after an Accident: Overcoming Obstacles', promoted by the Associação Nacional de Deficientes Sinistrados no Trabalho (ANDST). Combining the cross-reading of legal and administrative documents, legal doctrine, data from a survey by questionnaire, and the testimonies collected through interviews and compiled on journey maps, this paper tries to analytically reconstruct the main moments that constitute a post-sinister path. Thereto it describes the contacts in the institutional approach to reparation, and articulates it with the representations of the victims about their personal cases and the obstacles they have faced.

\section{ÍNDICE}

Keywords: accidents at work, post-accident pathways, legal repair, contacts with institutions Palabras claves: accidentes laborales, trayectos post-accidente, reparación legal, contactos con las instituciones

Mots-clés: accident de travail, parcours post-accident, réparation légale, contacts avec les institutions

Palavras-chave: acidentes de trabalho, percursos pós-sinistro, reparação legal, contactos com as instituições 


\section{AUTOR}

\section{VANESSA RODRIGUES}

Instituto de Sociologia da Universidade do Porto Faculdade de Letras Universidade do Porto Via

Panorâmica Edgar Cardoso 4150564 Porto Portugal vanessa.m.c.rodrigues@gmail.com 